\title{
Identification of Mycoplasmas of Human Origin
}

\author{
By HAVA HAAS, T. G. SACKS AND S. RAZIN \\ Department of Clinical Microbiology, The Hebrew University-Hadassah \\ Medical School, Jerusalem, Israel
}

(Accepted for publication 29 November 1967)

\begin{abstract}
SUMMARY
Fifty-five strains of the genus Mycoplasma were isolated from sputam of 95 patients suffering from various respiratory tract diseases. The polyacrylamide gel electrophoretic method was used to identify the isolated strains, in addition to the conventional biochemical methods and growth-inhibition by antisera. The electrophoretic patterns of the isolated strains were compared with those of known human mycoplasmas. The electrophoretic patterns obtained were species specific and highly reproducible. The results of the identification of the isolated strains by the gel electrophoretic method correlated well with those of the growth inhibition test. It is suggested that polyacrylamide gel electrophoresis of whole cell proteins might become a useful routine method for identification of mycoplasmas.

The most prevalent Mycoplasma found in the sputa was Mycoplasma salivarium, only four strains were identified as $M$. orale type I and one strain as $M$. pneumoniae. One strain was similar to, but not identical with, $M$. salivarium. The three oral anaerobic mycoplasmas $(M$. salivarium, $M$. orale types I and 2) showed a certain similarity when examined by the gel electrophoretic method, they may be genetically related to each other.
\end{abstract}

\section{INTRODUCTION}

Since it was established that the aetiological agent of primary atypical pneumonia associated with cold agglutinins is not a virus but a mycoplasma (Chanock, Hayflick \& Barile, 1962), interest in these organisms has markedly increased. Recent reports suggest that mycoplasmas may be associated with some diseases of as yet unknown aetiology. Hayflick \& Koprowsky (1965) reported the recovery of a mycoplasma directly from human leukaemic bone marrow, and their isolation has been reported from patients with Reiter's syndrome, rheumatoid arthritis and systemic lupus erythematosus (Bartholomew, 1965). There are indications that certain mycoplasmas, the T-strains, may be a cause of non-gonococcal urethritis (Csonka, Williams \& Corse, 1966; Shepard, 1967). Several Mycoplasma species are common inhabitants of the human oral cavity. Mycoplasma salivarium was isolated from the gingival sulci of almost all persons having natural dentitions, and it was concluded that this mycoplasma is a normal constituent of the anaerobic flora of the human oral cavity (Razin, Michmann \& Shimshoni, 1964). A strain more recently classified as $M$. orale type $\mathrm{I}$ is also a common inhabitant of the oropharynx; less common are $M$. orale types 2 and 3 and $M$. hominis type I (Taylor-Robinson, Canchola, Fox \& Chanock, I964; TaylorRobinson, Fox \& Chanock, I965; Purcell \& Chanock, 1967). The relationship of these strains to respiratory tract diseases has been investigated, but there is as yet no con- 
clusive evidence that they are able to produce disease in man (Glezen, Thornburg, Chin \& Wenner, 1967). The pathogenicity of $M$. pneumoniae, on the other hand, has been proved beyond doubt and it is rarely recovered from the oropharynx of healthy people (Chanock, 1965). M. pneumoniae also differs from all the other human mycoplasmas in its biochemical characteristics and in its antigenic structure.

The species identification of Mycoplasma strains, and in particular those isolated from the human oropharynx, is a frequent laboratory problem. The few biochemical tests available are of little help in species identification and at present this is based mainly on serological methods, which are time consuming and some of which frequently yield non-specific results. Nucleic acid homology techniques recently applied to Mycoplasma classification (Reich, Somerson, Rose \& Weissman, 1966) are still too complicated to be done in most laboratories. Rottem \& Razin (1967) showed that the membrane proteins of animal and saprophytic Mycoplasma strains produce electrophoretic patterns in polyacrylamide gels which are species specific and reproducible and can be used for identification purposes. Further studies (Razin \& Rottem, I967) have shown that the electrophoretic patterns of whole-cell proteins can serve the same purpose, simplifying the procedure considerably. The present report deals with the results of a survey of the Mycoplasma species isolated from sputa of patients suffering from various respiratory diseases, with special emphasis on the identification of the isolates by the new electrophoretic method as compared with the conventional biochemical and serological methods.

\section{METHODS}

Organisms. Mycoplasma pneumoniae, I553I; M. fermentans, I5474; M. hominis, type I, I5056; $M$. salivarium, I4277; $M$. orale type I, I5539 were obtained from the American Type Culture Collection (Rockville, Md.). Mycoplasma orale type 2 was kindly provided by R. M. Chanock (National Institutes of Health, Bethesda, Md.). Locally isolated strains were obtained as described below.

Cultural conditions. The medium used for the isolation and growth of the mycoplasmas was that of Chanock, Hayflick \& Barile (1962). Sputum specimens collected from 95 patients with respiratory tract infections, mainly bronchitis, were inoculated on two agar plates; one was incubated aerobically and the other anaerobically at $37^{\circ}$. The plates were inspected microscopically for Mycoplasma colonies every 2 days for up to 2I days. For polyacrylamide gel electrophoretic studies the reference and some of the isolated strains were grown in $200-500 \mathrm{ml}$. of liquid medium, and incubated for 5-10 days at $37^{\circ}$. In those cases where the local strains did not appear to be pure cultures on the basis of disc growth-inhibition tests, pure cultures were obtained from single colonies. The organisms were harvested by centrifugation at $13,000 \mathrm{~g}$ for $20 \mathrm{~min}$., washed three times and resuspended in I to $2 \mathrm{ml}$. of $0.25 \mathrm{M}-\mathrm{NaCl}$. The amount of cell protein was determined according to Lowry, Rosebrough, Farr \& Randall (195I). One mg. of cell protein was sufficient for polyacrylamide gel electrophoresis.

Biochemical characters. Glucose fermentation was examined on agar plates containing I \% (w/v) glucose and $0.0025 \%(w / v)$ phenol red. Reduction of 2,3,5-triphenyltetrazolium chloride (TTC) and growth inhibition by methylene blue were tested according to Kraybill \& Crawford (1965). Haemolytic activity of the mycoplasmas was tested by the method described by Somerson, Taylor-Robinson \& Chanock (1963). 
Serological characterization. Immune sera against the six reference Mycoplasma strains were prepared in rabbits by the method of Clyde (1964). All sera were stored at $-20^{\circ}$ until used. Growth inhibition tests were done with impregnated filter-paper discs (Clyde, 1964). Each isolate was tested for growth inhibition by antiserum against each of the reference strains. Inhibition was recorded when colony-free zones were observed around the filter-paper discs; these zones usually measured 5-I2 $\mathrm{mm}$. from the edge of the disc.

Polyacrylamide gel electrophoresis. Washed whole organisms were dissolved in phenol + acetic acid + water $(2+\mathrm{I}+0.5$, by vol.) and the dissolved material was run in polyacrylamide gels containing $35 \%$ acetic acid and 5 M-urea (Rottem \& Razin, I967).

\section{RESULTS}

Fifty-five of the 95 sputum specimens, were positive for Mycoplasma ( $57.9 \%$ ). One of the isolated strains grew aerobically, fermented glucose, reduced TTC aerobically, haemolysed guinea-pig erythrocytes and was not inhibited by $0.02 \%$ methylene blue,

Table I. Mycoplasma strains isolated from sputa of patients with various respiratory diseases as identified by growth-inhibition with monospecific antisera

$\begin{array}{lc}\text { Species } & \begin{array}{c}\text { No. of } \\ \text { strains }\end{array} \\ \text { Mycoplasma salivarium } & 48 \\ \text { M. orale type I } & 4 \\ \text { M. pneumoniae } & \text { I } \\ \text { identification doubtful } & 2 \\ \text { Total } & 55\end{array}$

presenting the biochemical characters of Mycoplasma pneumoniae. All the other 54 isolates grew only anaerobically and did not show any of the characters described above. Table $x$ summarizes the results of the growth inhibition tests by immune antisera. Forty-eight of the isolates $(87 \%)$ were identified by this method as $M$. salvarium and only four isolates $(7 \cdot 2 \%$ ) as $M$. orale type $\mathrm{I}$. The strain which presented the biochemical properties of $M$. pneumoniae was inhibited by the antiserum against $M$. pneumoniae only. Two strains could not be definitely identified because the zones of inhibition which they showed with antiserum against $M$. salivarium were very small compared to that obtained with the reference $M$. salivarium strain. They were not inhibited at all by any of the other immune sera.

The electrophoretic patterns of the cell proteins of the six reference strains were compared. Each of the species exhibited a characteristic pattern. Although the patterns of Mycoplasma salivarium and those of the $M$. orale type I and type 2 showed a certain similarity, a well-defined band near the top of the gel of $M$. salivarium which is characteristic for this species did not appear in either of the latter two (Fig. I). Nineteen of the local isolates were selected and their electrophoretic patterns compared to those of the reference strains. Thirteen locally isolated strains which were inhibited by $M$. salivarium antiserum were examined by polyacrylamide gel electrophoresis and showed patterns identical to each other and to that of $M$. salivarium. All the isolates inhibited by $M$. orale type I antiserum showed a pattern identical with that of the reference $M$. orale type I strain. The electrophoretic patterns of $M$. orale type I 
always lacked the well-defined upper band characteristic of $M$. salivarium. Of the two Mycoplasma isolates that were only slightly inhibited by antiserum against $M$. salivarium, one exhibited a pattern identical with that of the reference strain of $M$. salivarium, whereas the other showed a somewhat different pattern. The electrophoretic pattern of the isolate identified biochemically and serologically as $M$. pneumoniae was identical to that of the reference $M$. pneumoniae strain.

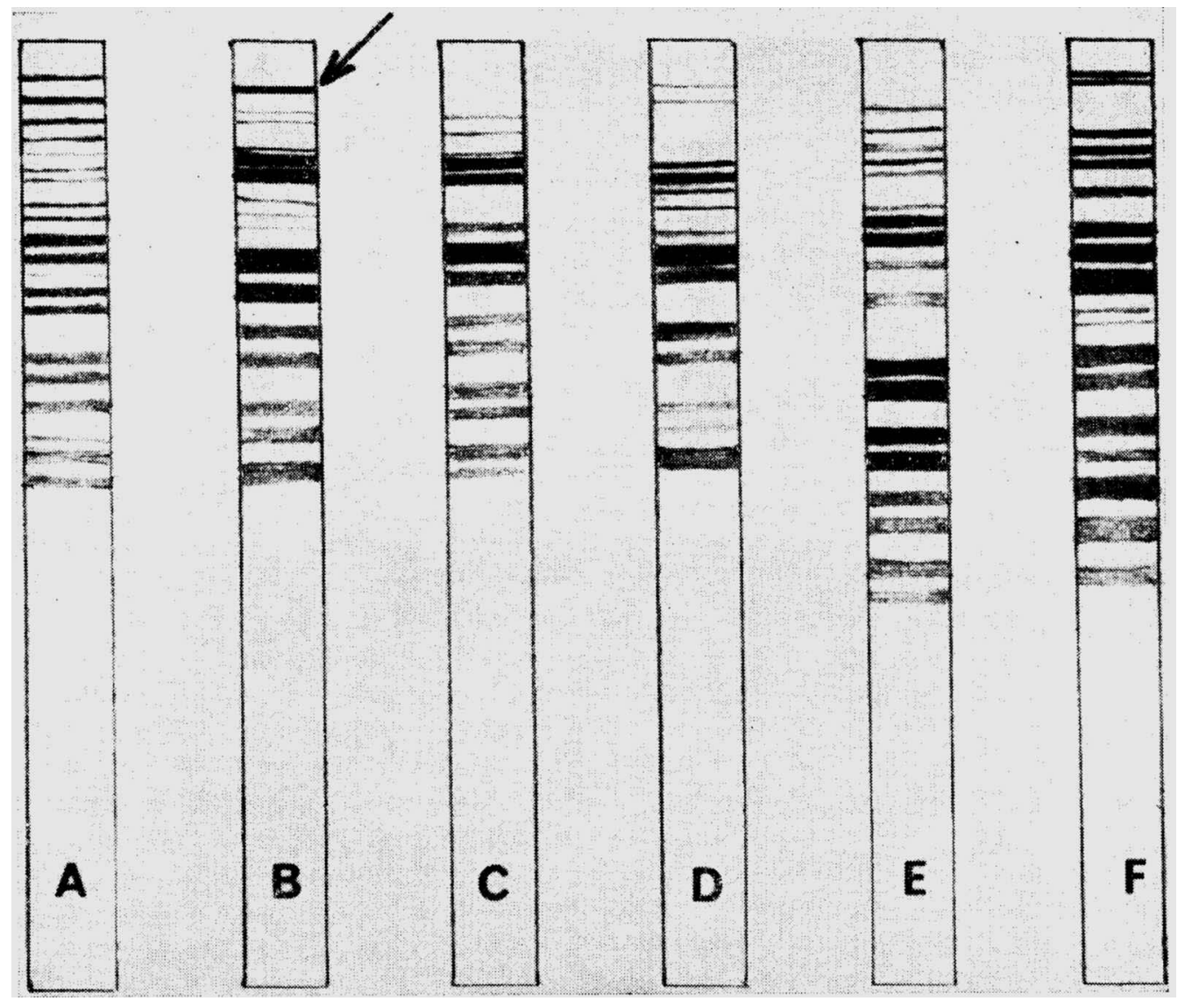

Fig. I. Schematic representation electrophoretic patterns of the cell proteins of type strains of human mycoplasmas. A $=M$. pneumoniae, ATCC 1553 I ; B $=M$. salivarium, ATCC I 4277; $\mathrm{C}=M$. orale type $\mathrm{I}, \mathrm{ATCC} \mathrm{I} 5539 ; \mathrm{D}=M$. orale type 2 (Chanock) $\mathrm{E}=M$. fermentans, ATCC $15474 ; \mathrm{F}=M$. hominis type I, ATCC I5056. The arrow indicates the characteristic upper band of $M$. salivarium.

The polyacrylamide gel electrophoresis patterns of the various mycoplasmas were reproducible in that identical patterns were obtained when the electrophoresis was repeated several times with different pools of the same strains.

\section{DISCUSSION}

The isolation of Mycoplasma strains other than Mycoplasma pneumoniae from the respiratory tract in health and disease has often been reported, but their role in 
producing disease is as yet unconfirmed. Mycoplasma hominis type I, however, was found to produce exudative pharyngitis in volunteers (Mufson et al. 1965). The mycoplasmas most frequently found in the oropharynx are $M$. salivarium and $M$. orale type I. According to some authors, $M$. orale type $\mathrm{I}$ is found much more frequently than $M$. salivarium (Glezen, Thornburg, Chin \& Wenner, 1967; Clyde, 1964), while others (Del Giudice, Robillard \& Carski, 1967) found, as we did, a higher incidence of $M$. salivarium than of $M$. orale type I. Mycoplasma pneumoniae is rarely found in the normal oropharynx. Its isolation is usually associated with disease. The strain isolated in the present study exhibited all the characteristics of $M$. pneumoniae. The person from whom it was isolated had complement-fixing antibodies against $M$. pneumoniae in a serum dilution of $\mathrm{I} / \mathrm{I00}$, but the diagnosis of primary atypical pneumonia was not confirmed clinically.

It is likely that the strains of Mycoplasma salivarium and Mycoplasma orale present in the sputum are salivary contaminants. The fact that they require an anaerobic or micro-aerophilic atmosphere for growth suggests that they might form part of the normal anaerobic flora of the gingival sulci. Evidence for this suggestion was presented before (Razin et al. 1964). Organick (1967) showed that the percentage of Mycoplasma isolates in bronchial swabs obtained by bronchoscopy was much lower than in pharyngeal swabs. Since the Mycoplasma isolates belonged to the same species in both cases, they suggested that the mycoplasmas occurring in the bronchial swabs resulted from contamination by pharyngeal secretions. Organick (1967) also claimed that the mycoplasmas do not play any causative role in chronic bronchitis.

Growth inhibition by specific antiserum yields highly specific results in the identification of Mycoplasma species (Hayflick \& Chanock, 1965). Unfortunately this method has some disadvantages. It requires the preparation of potent immune sera and the results of the growth inhibition depend to some extent on the size of the inoculum. The polyacrylamide gel electrophoretic method used in this study seems to be adequate for the rapid identification of new isolates and eliminates the need for expensive antisera. The results obtained by the gel electrophoretic method are reproducible and correlate well with those obtained by the growth inhibition test. The electrophoretic pattern of Mycoplasma salivarium and $M$. orale types I and 2 resembled each other and formed a distinct group in comparison with the other human mycoplasmas. This finding suggests that the oral anaerobic mycoplasmas may be genetically related to each other, since the composition of cell proteins may reflect genetic relatedness. Complementfixation tests showed a high level one way cross reaction between $M$. salivarium and $M$. orale (Taylor-Robinson et al. 1964). On the other hand, the few available results of nucleic acid homology determinations showed only a low degree of cross-reaction between the anaerobic oral mycoplasmas (Reich et al. 1966). The one strain which could not be definitely identified as $M$. salivarium by the growth inhibition test and which also differed from $M$. salivarium in its electrophoretic pattern seems nevertheless to be more closely related to $M$. salivarium than to the other human mycoplasmas. The possibility that this was a mixed culture cannot be ruled out, although the disc growth inhibition test did not indicate the presence of more than one type. These findings suggest the existence of different types of $M$. salivarium as was found for $M$. hominis type I (Reich, Somerson, Rose \& Weissman, I966). Further study is needed before any conclusion can be reached in this matter. 
This work was supported in part by a grant from the Joint Research Fund of Hebrew University-Hadassah Medical School, and in part by grant 5/B-5 from the Ford Foundation.

\section{REFERENCES}

BARTHOLOMEW, L. E. (1965). Isolation and characterization of mycoplasmas (PPLO) from patients with rheumatoid arthritis, systemic lupus erythematosus and Reiter's syndrome. Arthr. \& Rheum. $8,376$.

Chanock, R. M., Hayflick, L. \& Barile, M. F. (I962). Growth on artificial medium of agent associated with atypical pneumonia and its identification as PPLO. Proc. natn. Acad. Sci. U.S.A.48, 4I.

CHANOCK, R. M. (1965). Mycoplasma infections of man. New Engl. J. Med. 273, I199.

CLYDE, W. A. JUN. (1964). Mycoplasma species identification based upon growth inhibition by specific antisera. J. Immunol. 92, 958.

Csonka, G. W., Williams, R. E. O. \& Corse, J. (1966). T-strain Mycoplasma in non-gonococcal urethritis. Lancet ii, $\mathbf{2} 292$.

Del GiUdice, R. A., Robillard, N. F. \& CARSKi, T. R .(1967). Immunofluorescence identification of Mycoplasma on agar by use of incident illumination. J. Bact. 93, 1205.

Glezen, W. P., Thornburg, G., Chin, T. D. Y.\& Wenner, H. A. (1967). Significance of Mycoplasma infections in children with respiratory disease. Pediatrics $39,516$.

HAYFLICK, L. \& CHANOCK, R. M. (1965). Mycoplasma species of man. Bact. Rev. 29, 185 .

HAYFLICK, L. \& KoPRowsKY, H. (1965). Direct agar isolation of mycoplasma from human leukemic bone marrow. Nature, Lond. 205, 713.

Kraybill, W. H. \& Crawford, Y. E. (1965). A selective medium and color test for Mycoplasma pneumoniae. Proc. Soc. exp. Biol. Med. I18, 965.

Lowry, O. H., Rosebrough, N., Farr, A. L. \& Randall, R. (I95I). Protein measurement with the Folin phenol reagent. J. biol. Chem. 193, 265.

Mufson, M. A., Ludwig, W. M., Purcell, R. H., Cate, T. R., Taylor-Robinson, D. \& Chanock, R. M. (1965). Exudative pharyngitis following experimental Mycoplasma hominis type I infection. J. Am. med. Ass. 192, 1146.

ORGANICK, A. B. (1967). Isolation and identification of Mycoplasma from the lower respiratory tract in bronchoscopy patients. Am. Rev. resp. Dis. 95, 61 8 .

Purcell, R. H., \& Chanock, R. M. (I967). Role of mycoplasmas in human respiratory disease. Med. Clin. N. Am. 5I, 79I.

RAZIN, S. \& RotTem, S. (I967). Identification of Mycoplasma and other micro-organisms by polyacrylamide gel electrophoresis of cell proteins. J. Bact. 94, 1807.

Razin, S., MichmanN, J. \& Shimshoni, Z. (1964). The occurrence of Mycoplasma (pleuro-pneumonialike organisms, PPLO) in the oral cavity of dentulous and edentulous subjects. J. Dent. Res. 43, 402.

Reich, P. R., Somerson, N. L., Rose, J. A. \& Weissman, S. M. (1966). Genetic relatedness among mycoplasmas as determined by nucleic acid homology. J. Bact. 9I, 153 .

Reich, P. R., Somerson, N. L., Hybner, C. J., Chanock, R. M. \& Weissman, S. M. (I966). Genetic differentiation by nucleic acid homology. I. Relationships among Mycoplasma species of man. J. Bact. 92, 302.

RotTem, S. \& RAZIN, S. (1967). Electrophoretic patterns of membrane proteins of Mycoplasma. J. Bact. 94, 359.

ShePARD, M. C. (I967). Cultivation and properties of T-strains of Mycoplasma associated with nongonococcal urethritis. Ann. N.Y. Acad. Sci. 143, 505.

Somerson, N. L., TAYlor-Robinson, D. \& Chanock, R. M. (1963). Hemolysin production as aid in identification and quantitation of Eaton agent (Mycoplasma pneumoniae). Am. J. Hyg. 77, I22.

TAYLOR-RoBinson, D., Fox, H. \& CHANOCK, R. M. (I965). Characterization of a newly identified Mycoplasma from the human oropharynx. Am. J. Hyg. 8I, 180.

Taylor-Robinson, D., Canchola, J., Fox, H. \& Chanock, R. M. (1964). A newly identified oral Mycoplasma (M. orale) and its relationship to other human mycoplasmas. Am. J. Hyg. 8o, I 35. 